\title{
RECONHECIMENTO, RELIGIÃO E SECULARISMO EM CHARLES TAYLOR
}

\author{
Recognition, religion and secularism in Charles Taylor
}

Reconocimiento, religión y el secularismo en Charles Taylor

Juliano Cordeiro da Costa Oliveira'

\section{Resumo}

O artigo objetiva investigar, à luz do filósofo Charles Taylor, a questão do reconhecimento dos sujeitos a partir da relação entre secularismo e religião. $O$ fio condutor do pensamento de Taylor é o comunitarismo. Este se relaciona com a ideia de que o contexto das normas que regem uma sociedade deve ser o de uma comunidade que, em seus valores, práticas e instituições formam um horizonte constitutivo para a identidade de seus membros. Somente assim seria possível colocar as questões da justiça e, então, responder sobre o que é bom e o que deve valer para a comunidade. Segundo Taylor, os homens são seres expressivos porque pertencem a uma cultura que é nutrida e transmitida no interior de uma comunidade. Taylor parte da crítica hegeliana ao formalismo kantiano que deslocou o sujeito da comunidade, da história e da cultura, gerando demandas de reconhecimento. Ele enfatiza que a religião, por exemplo, ainda se relaciona com a formação das diversas identidades, tal qual uma esfera essencial na constituição dos sujeitos, mesmo em sociedades secularizadas. Taylor destaca a existência de múltiplas modernidades, uma vez que culturas não ocidentais foram modernizadas à sua

\footnotetext{
1 Doutor em Filosofia pela Universidade Federal do Ceará (UFC), com doutorado sanduíche pela Ludwig-Maximilian-Universität (LMU), em Munique, Alemanha. Pós-doutorando pela Universidade Federal do Piauí (UFPI) e bolsista Capes. https://orcid.org/0000-0002-08446731.E-mail: julianopesquisa81@gmail.com; julianocordeiro81@gmail.com.
} 
maneira, sem a necessária separação entre identidades secularizadas e religiosas. 0 filósofo também defende uma redefinição do secularismo que valorize as religiões como fontes essenciais e indispensáveis para diversos sujeitos que se formaram a partir de outras linguagens, culturas e tradições diversas da concepção tradicional de secularismo. Como, então, pensar a questão do reconhecimento, no âmbito da relação entre secularismo e religião?

Palavras-chave: Reconhecimento. Secularismo. Religião. Charles Taylor.

\section{Abstract}

The article aims to investigate, in the light of the philosopher Charles Taylor, the question of recognition of the subjects from the relation between secularism and religion. The guiding principle of Taylor's thinking is communitarianism. This one is related to the idea that the context of the norms that govern a society must be that of a community which in its values, practices and institutions form a constitutive horizon for the identity of its members. Only this way it would be possible to consider the questions of justice and then to answer about what is good and what should be worth for the community. According to Taylor, men are expressive beings because they belong to a culture that is nurtured and transmitted within a community. Taylor starts from the Hegelian critique of the Kantian formalism which displaced the subject from the community, from history and from culture, generating demands for recognition. He emphasizes that religion, for example, is still related to the formation of several identities, just as an essential sphere in the constitution of subjects, even in secularized societies. Taylor emphasizes the existence of multiple modernities, once non-Western cultures were modernized in their own way, without the necessary separation between secularized and religious identities. Taylor advocates a redefinition of secularism which values religions as essential and indispensable sources for diverse subjects who have formed from other languages, cultures and traditions, different from the traditional conception of secularism. How, then, to think about the question of recognition, within the framework of the relationship between secularism and religion?

Keywords: Recognition. Secularism. Religion. Charles Taylor.

\section{Resumen}

El artículo tiene como objetivo investigar, teniendo en cuenta el filósofo Charles Taylor, la cuestión del reconocimiento de los sujetos de la relación entre laicismo y religión. El hilo del pensamiento de Taylor es el comunitarismo. Esto se relaciona 
con la idea de que el contexto de las normas que rigen una sociedad debe ser una comunidad que, en sus valores, prácticas y las instituciones forman un horizonte de constituición de la identidad de sus membros. Sólo de esta manera será posible poner las cuestiones de justicia y luego responder sobre lo que es bueno y lo que debe contar para la comunidade. Según Taylor, los hombres son seres expresivos, porque pertenecen a una cultura que se nutre y es además transmitida dentro de una comunidad. Parte de la crítica hegeliana que el formalismo kantiano que cambió de puesto el sujeto, de su comunidad, historia y cultura, lo que generó demandas por el reconocimiento. Enfatiza que la religión, por ejemplo, todavía se refiere a la formación de las identidades diversas, como una esfera fundamental en la constitución del sujeto, incluso en sociedades secularizadas. Taylor pone de relieve la existencia de múltiples modernidades, puesto que las culturas no occidentales fueron modernizadas a su manera, sin la separación necesaria entre identidades seculares y religiosas. Taylor aboga por una redefinición del secularismo que realza las religiones como fuente esencial e indispensable para diversos sujetos que se formaran a partir de otras linguagens, culturas y tradiciones distintas de diseño tradicional de secularismo. Como, entonces, pensar la cuestión del reconocimieto, en el contexto de la relación entre el secularismo y la religión?

Palabras clave: Reconocimiento. Secularismo. Religión. Charles Taylor.

\section{Introdução}

Para Marcel Gauchet ${ }^{2}$, assistimos a um duplo processo acerca do religioso na contemporaneidade: de um lado, a saída da religião; de outro, a individualização do crer. Com a modernidade, houve uma saída da religião do espaço público, estando ela restrita ao âmbito individual. Segundo Gauchet, é possível, assim, compreender ao mesmo tempo tanto a saída da religião do espaço público como também sua permanência, mas apenas nas esferas individuais.

Gauchet argumenta que a emergência da democracia no Ocidente só pode ser compreendida no quadro de um processo de saída da religião. Isso seria algo irreversível, uma vez que não há como voltar aos fundamentos incondicionais das religiões em sociedades democráticas e pluralistas: “Deus está separado. Ele não intervém nos assuntos políticos dos

2 GAUCHET, M. Le désenchantement du monde: une historie politique de la religion. Paris: Gallimard, 1985. p. 292. 
homens." ${ }^{3}$ Não podemos falar, porém, no desaparecimento das religiões nas sociedades modernas. "Isso não significa que o religioso deva parar de falar aos indivíduos ${ }^{4 \prime}$. A religião não perdeu, apesar da secularização, sua condição de reserva de sentido para vários sujeitos, inclusive como parte constituinte de suas identidades.

Nesse contexto, de acordo com Peter Berger 5 , a religião continua a ter relevância como fonte de sentido de vida para vários sujeitos, mesmo com a secularização. Berger propõe um novo paradigma que seja capaz de lidar com dois pluralismos, a saber: a coexistência de diferentes religiões e a coexistência de discursos religiosos e seculares. "Esta coexistência ocorre não somente nas mentes dos indivíduos, mas também no espaço social"6. Berger argumenta que a secularidade ocidental não é a única forma de modernidade: haveria outras versões da modernidade, nas quais se concede à religião um lugar mais central. Afinal, a tradição religiosa é igualmente uma memória social coletiva7.

Posto isso, Charles Taylor, na filosofia contemporânea, enfatiza que a religião ainda se relaciona com a formação das diversas identidades, tal qual uma esfera essencial na constituição dos sujeitos, mesmo em sociedades secularizadas. Taylor destaca a existência de múltiplas modernidades, uma vez que culturas não ocidentais foram modernizadas à sua maneira, sem a necessária separação entre identidades secularizadas e religiosas.

A modernidade ocidental seria apenas um imaginário social possível perante tantos outros, isto é, uma forma de ser dentre várias. "A insistência ainda é a de que os espaços públicos nos quais os cidadãos se encontram

3 GAUCHET, M. La religion dans la démocratie: parcours de la laïcité. Paris: Gallimard, 1998. p. 61.

4 GAUCHET, M. Le désenchantement du monde: une historie politique de la religion. Paris: Gallimard, 1985. p. 292.

5 BERGER, P. Os múltiplos altares da modernidade: rumo a um paradigma da religião numa época pluralista. Petrópolis: Vozes, 2017a. p. 9.

6 BERGER, P. Os múltiplos altares da modernidade: rumo a um paradigma da religião numa época pluralista. Petrópolis: Vozes, 2017a. p. 9.

7 BERGER, P. O Imperativo Herético: possibilidades contemporâneas da afirmação religiosa. Petrópolis: Vozes, 2017b. p. 70. 
devem ser purificados de qualquer referência religiosa"8. Taylor defende uma redefinição do secularismo que valorize as religiões como fontes essenciais e indispensáveis para diversos sujeitos que se formaram a partir de outras linguagens, culturas e tradições diversas da concepção tradicional de secularismo.

Em Taylor, a identidade designa algo como uma compreensão de quem somos, de nossas características fundamentais como seres humanos. $\mathrm{O}$ reconhecimento não é mera cortesia que devemos conceder às pessoas. "É uma necessidade humana vital" . Como, então, pensar a religião e a exigência de reconhecimento das identidades no horizonte de um mundo pluralista, de crentes das mais diversas religiões e não crentes, uma vez que, como caracteriza Michael Walzer ${ }^{10}$, a coexistência de grupos diversos é uma característica da modernidade?

\section{Identidade, Comunidade e Reconhecimento}

O fio condutor do pensamento de Charles Taylor é o comunitarismo. Este se relaciona com a ideia de que o contexto das normas que regem uma sociedade deve ser o de uma comunidade. Seus valores e suas práticas e instituições formam um horizonte constitutivo para a identidade de seus membros. Somente assim seria possível colocar as questões da justiça e, então, responder sobre o que é bom e o que deve valer para a comunidade. "Nosso relato é moldado o tempo inteiro por aquilo que compreendemos ser a realidade do caso"1". Segundo Taylor, os homens são seres expressivos, porque pertencem a uma cultura que é "sustentada, nutrida e transmitida no interior de uma comunidade"12.

\footnotetext{
8 TAYLOR, C. O que significa secularismo? In: ARAÚJO, L.; MARTINEZ, M.; PEREIRA, T. (org.). Esfera pública e secularismo: ensaios de filosofia política. Rio de Janeiro: UERJ, 2012. p. 162.

9 TAYLOR, C. Argumentos Filosóficos. São Paulo: Edições Loyola, 200o. p. 242.

10 WALZER, M. Da Tolerância. São Paulo: Martins Fontes, 1999. p. 114.

1 TAYLOR, C. Argumentos Filosóficos. São Paulo: Edições Loyola, 200o. p. 169.

12 TAYLOR, C. Hegel e a Sociedade Moderna. São Paulo: Edições Loyola, 2005. p. 13.
} 
No comunitarismo, princípios de justiça que regem a sociedade resultam de certo contexto. Taylor parte da crítica hegeliana ao formalismo kantiano que deslocou o sujeito da comunidade, da história e da cultura, gerando demandas de reconhecimento.

O individualismo começa, como afirma Hegel, quando os homens deixam de se identificar com a vida da comunidade, quando eles "refletem", ou seja, quando se voltam para si mesmos, e se veem de modo mais importante como indivíduos detentores de objetivos individuais ${ }^{13}$.

Como sabemos, "o sujeito moderno é autodefinitório"14, uma vez que a autoconsciência significa a autodeterminação de si, do próprio eu alheio às forças externas, tal qual um self autêntico e original. A cultura moderna, por assim dizer, desenvolveu concepções de individualismo que retratam a pessoa humana como um ser que encontra suas coordenadas apenas dentro de si mesmo, sem nenhuma influência de outras mediações ou redes de interlocução' ${ }^{15}$.

A preocupação de Taylor é demonstrar que o indivíduo está desde sempre situado em uma vivência comunitária que fornece os elementos significativos para a construção de seu self, sempre pertencente a um contexto fundamental. Portanto, a ideia do bem é determinante para sermos plenamente ${ }^{16}$. 0 hegelianismo de Taylor diz respeito à consideração que ele faz das influências da vida comunitária na esfera de reconhecimento dos sujeitos.

Em Taylor, como destaca Michael Walzer ${ }^{17}$, a cultura de um povo é uma esfera de reconhecimento determinante à medida que a subjetividade é um processo relacional, não sendo uma pura identidade consigo mesma,

\footnotetext{
13 TAYLOR, C. Hegel e a Sociedade Moderna. São Paulo: Edições Loyola, 2005. p. 117.

14 TAYLOR, C. Hegel: sistema, método e estrutura. São Paulo: Realizações Editora, 2014. p. 26.

15 TAYLOR, C. As fontes do self: a constituição da identidade moderna. 4. ed. São Paulo: Edições Loyola, 2013. p. 56.

16 TAYLOR, C. A Ética da Autenticidade. São Paulo: Realizações Editora, 2011b. p. 36.

17 WALZER, M. Da Tolerância. São Paulo: Martins Fontes, 1999. p. 62.
} 
mas mediada por processos de interação no âmbito de uma comunidade. A subjetividade é o movimento de saída de si e de retorno a si pela mediação da alteridade: só no outro e por meio do outro a subjetividade se constitui como tal ${ }^{18}$. Para Paul Ricoeur, por exemplo, a identidade não implica nenhuma asserção "a um pretenso núcleo não mutante da personalidade"19. O homem é um ser inserido numa comunidade, num mundo culturalmente herdado, transmitido de geração a geração.

A vida comunitária aparece como horizonte de possibilidade para os indivíduos elaborarem as suas identidades, pois é nela que os indivíduos encontram as bases culturais que sustentam as suas indagações de sua vida ${ }^{20}$.

Por isso, o reconhecimento, em Taylor, tornou-se uma questão primordial na modernidade, à medida que o sujeito se vê separado do outro e de sua própria comunidade. Em outros termos, a modernidade cindiu o sujeito do mundo e dos outros sujeitos. Nas palavras de Taylor, "o não reconhecimento ou o reconhecimento errôneo podem causar danos, podem ser uma forma de opressão, aprisionando alguém numa modalidade de ser falsa, distorcida e redutora"21.

Assim, a formação do self "está intrinsecamente ligada a uma visão de bem e de vida boa, e constituem o centro do pensamento de Taylor"22. Quando um bem constitutivo de uma cultura não é articulado, corre-se o risco de perder fontes morais que alimentam a vida dos sujeitos. É necessária uma ontologia moral, isto é, uma teoria do bem, a fim de que haja uma conexão entre sentidos do eu e visões morais, ou seja, entre identidade e bem, algo determinante para a formação do self.

18 OLIVEIRA, M. Ética e Sociabilidade. 3. ed. São Paulo: Loyola, 2003. p. 185.

19 RICOEUR, P. O Si Mesmo como um Outro. Campinas: Papirus Editora, 1991. p. 13.

20 ARAÚJO, P. Charles Taylor: para uma ética do reconhecimento. São Paulo: Loyola, 2004. p. 141.

21 TAYLOR, C. Argumentos Filosóficos. São Paulo: Edições Loyola, 200o. p. 241.

22 BINJA, E. Multiculturalismo: a identidade do sujeito nas tensões sociais contemporâneas em Charles Taylor. São Paulo: Editora Liberars, 2015. p. 12. 
Taylor entende a ação moral como o desejo articulado linguisticamente do agente em busca da realização do bem, a dimensão existencial que dá dignidade à sua identidade humana. O bem aparece como meta a ser alcançada pelas avaliações que o agente faz ao agir. O que está em jogo é a própria identidade do self como agente moral.

Logo, a cultura que vive em nossa sociedade molda nossa experiência privada e constitui nossa experiência pública, que, por sua vez, interage profundamente com a experiência privada. De modo que não é uma proposição extravagante afirmar que nós somos o que somos em virtude de participar da vida mais ampla de nossa sociedade ${ }^{23}$.

Deste modo, Taylor compreende que o homem elabora e expressa sua identidade também por meio de sua linguagem. À luz de Herder, ele exemplifica que a linguagem não pode ser vista apenas como um conjunto de sinais, mas como o meio de expressão de certo modo de ver e experimentar, e mesmo viver. "Logo, não pode haver pensamento sem linguagem, e, com efeito, as linguagens de diferentes povos refletem suas diferentes visões das coisas" ${ }^{\prime 2}$. Encontrar uma linguagem para a diversidade cultural é encontrar uma linguagem para modernidades alternativas ou encontrar uma forma de compreender a modernidade que reserve um lugar para essas alternativas. Seria possível, por isso, compreender "as diferenças com relação às outras culturas"25.

Por conseguinte, os sujeitos têm suas identidades definidas por algum compromisso moral ou espiritual que se expressa e se forma em uma determinada linguagem e modo de vida. A linguagem é a própria esfera de expressão e constituição de um modo de ser no mundo, bem como das identidades formadoras dos sujeitos. "Estudar pessoas é estudar seres

\footnotetext{
23 TAYLOR, C. Hegel e a Sociedade Moderna. São Paulo: Edições Loyola, 2005. p. 113.

24 TAYLOR, C. Hegel e a Sociedade Moderna. São Paulo: Edições Loyola, 2005. p. 31.

25 TAYLOR, C. Argumentos Filosóficos. São Paulo: Edições Loyola, 2000, p. 11-12.
} 
que só existem em certa linguagem"26. A linguagem serve para instaurar espaços de ação comum em vários níveis, tanto íntimos como públicos. Isso significa que nossa identidade nunca é definida apenas em termos de nossas propriedades individuais ${ }^{27}$. Ela também nos situa em algum espaço social. Com isso, os sujeitos definem suas identidades pela nação ou tradição a que pertencem.

O que as pessoas estão dizendo com isso não é apenas que estão fortemente ligadas a essa concepção espiritual ou antecedentes, mas que isso oferece a estrutura dentro da qual podem determinar que posição defendem em questões sobre o que é bom, ou válido, ou admirável ou de valor ${ }^{28}$.

Uma crise de identidade, com isso, é uma forma aguda de desorientação. Aqui, identidade e orientação para uma vida boa relacionam-se diretamente. Perder essa orientação ou não a ter encontrado é não saber quem se é. "E essa orientação, uma vez conseguida define a posição a partir da qual você responde e, portanto, sua identidade"29. Ela é aquilo que nos permite definir o que se é e o que não é importante para nós.

Assim sendo, minha descoberta de minha identidade não implica uma produção minha de minha própria identidade no isolamento; significa que eu a negocio por meio do diálogo, parte aberto, parte interno, com o outro. (...) Minha própria identidade depende crucialmente de minhas relações dialógicas com os outros ${ }^{30}$.

\footnotetext{
${ }^{26}$ TAYLOR, C. As fontes do self: a constituição da identidade moderna. 4. ed. São Paulo: Edições Loyola, 2013. p. 53.

27 TAYLOR, C. Argumentos Filosóficos. São Paulo: Edições Loyola, 2000. p. 189.

28 TAYLOR, C. As fontes do self: a constituição da identidade moderna. 4. ed. São Paulo: Edições Loyola, 2013. p. 44.

29 TAYLOR, C. As fontes do self: a constituição da identidade moderna. 4. ed. São Paulo: Edições Loyola, 2013. p. 46.

30 TAYLOR, C. Argumentos Filosóficos. São Paulo: Edições Loyola, 2000. p. 248.
} 
Em Taylor, o indivíduo não age motivado por meras escolhas quantitativas, mas por avaliações do desejo que permite ao agente decidir qual a direção a ser tomada no ato de agir. Há uma avaliação entre dois desejos: uma fraca e outra forte. Na primeira, para algo ser julgado como bom é necessário somente que seja desejado. Não há, portanto, o comprometimento com as formas valorativas que podem construir o próprio desejo. Na avaliação fraca (desejos de primeira ordem), o julgamento de algo como bom ocorre apenas no plano do desejo desenraizado de valor, fundado apenas na contingência, sem uma ação responsável.

Já na avaliação forte (desejos de segunda ordem) há expressões valorativas da identidade do sujeito humano, caracterizadas como um modo reflexivo dos desejos. Na avaliação forte, não se trata de mera satisfação contingente, mas daquilo que dá consistência às diversas formas de concepção humana. Afinal, os desejos de segunda ordem não refletem uma instância imediata, mas se relacionam com o pano de fundo ontológico, que constitui a identidade essencial dos sujeitos.

Não é à toa que, em As fontes do self, Taylor tem como principal conceito a avaliação forte, que irá, ao mesmo tempo, sustentar e desenvolver todas as suas teses sobre a construção do self moderno. A avaliação forte traz consigo a possibilidade de articulação da identidade da pessoa, fazendo com que esta deseje elaborar um modo de vida. ${ }^{31} \mathrm{Na}$ avaliação forte pergunta-se por uma vida significativa em contraposição a uma voltada apenas a questões triviais.32 Para compreender nosso mundo moral, temos de ver não só que ideias e quadros descritivos subjazem a nosso sentido de respeito pelos outros, mas também aqueles que alicerçam nossas noções de uma vida plena.

Nossas distinções qualitativas, na qualidade de definições do bem, oferecem antes razões no seguinte sentido: articulá-las

\footnotetext{
31 ARAÚJO, P. Charles Taylor: para uma ética do reconhecimento. São Paulo: Loyola, 2004. p. 90.

32 TAYLOR, C. As fontes do self: a constituição da identidade moderna. 4. ed. São Paulo: Edições Loyola, 2013. p. 29.
} 


\begin{abstract}
é articular o que está na base de nossas escolhas, inclinações e intuições éticas. É determinar de maneira precisa aquilo que apreendo vagamente quando vejo que $A$ é certo, ou que $X$ é errado ou que $Y$ é valioso e merece ser preservado, e assim por diante. É articular o sentido moral de nossas ações ${ }^{33}$.
\end{abstract}

A partir disso, o reconhecimento e a constituição dos sujeitos encontram-se numa tradição específica, portadora de uma pré-compreensão concreta da realidade, radicada na nacionalidade, na língua, na cultura e na história de um povo. Taylor ${ }^{34}$ conceitua, seguindo seu comunitarismo, o que denomina de imaginário social, como uma instância essencial na formação dos sujeitos, tal qual um etos fundamental na constituição das subjetividades pertencentes a uma comunidade.

\title{
2 Os imaginários sociais como instâncias constitutivas dos sujeitos
}

Em Taylor, o imaginário social não se expressa apenas em termos teóricos, mas apoia-se em imagens e narrativas que nos guiam coletivamente e nos formam enquanto sujeitos pertencentes a uma comunidade, cultura e tradição. Uma teoria, ao contrário do imaginário social, é algo apenas de posse de uma minoria, ao passo que o imaginário social é partilhado por grandes grupos sociais, como um horizonte de sentido de vida e reconhecimento social, essenciais para a formação dos sujeitos: "o imaginário social é a compreensão que possibilita práticas comuns e um sentido de legitimidade amplamente partilhado"35. A subjetividade seria uma instância sempre pertencente a uma comunidade e a um imaginário.

\footnotetext{
33 TAYLOR, C. As fontes do self: a constituição da identidade moderna. 4. ed. São Paulo: Edições Loyola, 2013. p. 108.

34 TAYLOR, C. Imaginários sociais modernos. Lisboa: Edições Texto \& Grafia, 2010b. p. 31.

35 TAYLOR, C. Imaginários sociais modernos. Lisboa: Edições Texto \& Grafia, 2010b. p. 31.
} 
Ela nunca pode ser pensada como uma categoria neutra ou deslocada do sentido primeiro que funda seu pertencimento a uma tradição.

Os sujeitos atuam no imaginário social muito antes de teorizarem acerca de si mesmos. O imaginário social incorpora expectativas que temos uns dos outros, mediante imagens normativas profundas, relacionando-se com práticas coletivas que constituem a vida social, tal qual uma esfera de reconhecimento dos sujeitos e um reservatório de sentido de vida partilhado conjuntamente. Do contrário, Taylor ${ }^{36}$ alerta para uma possível perda de horizonte de sentido de vida, tal qual um aniquilamento da existência. Encontrar um sentido para a vida depende, sobretudo, da construção de expressões significativas e adequadas para sujeitos plenos de relações que o constituem.

De acordo com Taylor, somos, portanto, um self, à medida que certas questões nos importam. O que sou enquanto self, minha identidade, define-se essencialmente pela maneira como as coisas têm significações para meus imaginários sociais: "a questão de minha identidade é resolvida apenas mediante uma linguagem de interpretação que vim a aceitar como articulação válida dessas questões" ${ }^{37}$. Portanto, somos um self quando nos movemos em certo espaço de indagações e imaginários, porque buscamos e encontramos uma orientação para o bem.

Como não podemos prescindir de uma orientação para o bem, e como não podemos ser indiferentes à nossa posição relativamente a esse bem, e como esse lugar é algo que deve sempre mudar e tornar-se, tem de surgir para nós a questão da direção de nossa vida ${ }^{38}$.

\footnotetext{
${ }^{36}$ TAYLOR, C. As fontes do self: a constituição da identidade moderna. 4. ed. São Paulo: Edições Loyola, 2013. p. 32.

37 TAYLOR, C. As fontes do self: a constituição da identidade moderna. 4. ed. São Paulo: Edições Loyola, 2013. p. 52.

${ }_{38}$ TAYLOR, C. As fontes do self: a constituição da identidade moderna. 4. ed. São Paulo: Edições Loyola, 2013. p. 70.
} 
Ser um self é inseparável da existência num espaço de questões morais, que têm a ver com a identidade e com aquilo que devemos ser a partir de uma herança formadora de nossas tradições, linguagens, culturas e imaginários sociais. "É ser capaz de encontrar sua própria posição nesse espaço, conseguir ocupá-lo, ser uma dentro dele"39. Logo, seria preciso uma ética articulada por conceitos ontológicos, assumindo uma noção de bem socialmente representativa: o indivíduo "serve a um objetivo mais amplo que é o fundamento de sua identidade, pois ele só é quem é no contexto dessa vida mais ampla"40.

Taylor fala acerca da existência de múltiplas modernidades, uma vez que culturas não ocidentais foram modernizadas à sua maneira. A modernidade ocidental, por exemplo, seria apenas um imaginário social frente a tantos outros: "as diferenças entre as múltiplas modernidades de hoje hão de entender-se sob o ponto de vista dos divergentes imaginários sociais implicados" ${ }^{\prime 4}$. Nesse contexto, Taylor defende uma redefinição do secularismo que valorize as religiões como fontes essenciais e indispensáveis para diversos sujeitos que se formaram a partir de outras linguagens e tradições, diversas da concepção tradicional de secularismo, como veremos abaixo. Partiremos, nesse momento, da análise dialética de Hegel acerca da relação entre cristianismo, lluminismo e Revolução Francesa, mostrando sua crítica a interpretações unilaterais de tais acontecimentos ao longo da história, algo determinante para Taylor e seu pensamento.

\section{Hegel e a Dialética entre Religião e Iluminismo}

Hegel já havia refletido acerca da relação entre secularismo e religião, principalmente por meio de suas análises acerca da Revolução Francesa

\footnotetext{
39 TAYLOR, C. As fontes do self: a constituição da identidade moderna. 4. ed. São Paulo: Edições Loyola, 2013. p. 150.

40 TAYLOR, C. Hegel e a sociedade moderna. São Paulo: Edições Loyola, 2005. p. 112.

${ }^{41}$ TAYLOR, C. Imaginários sociais modernos. Lisboa: Edições Texto \& Grafia, 2010b. p. 11.
} 
e do lluminismo. Ele propõe uma rigorosa dialética entre lluminismo e religião, mostrando a insuficiência de caminhos unilaterais a serem seguidos tanto pelo cristianismo como pelo lluminismo. Hegel destaca o papel motivacional das religiões para os sujeitos, mesmo numa sociedade secularizada. O lluminismo, então, não pode simplesmente querer abolir as religiões, isto é, um outro. As religiões, no entanto, não podem negar a conquista histórica da modernidade e do lluminismo. Seria preciso, assim, pensarmos um terceiro caminho que considere, ao mesmo tempo, o papel motivacional das religiões para vários sujeitos, como também a conquista histórica da modernidade e do Estado secular.

\begin{abstract}
Aliás, não é difícil ver que nosso tempo é sim tempo de nascimento e trânsito para uma nova época. $O$ espírito rompeu com o mundo de seu ser-aí e de seu representar, que até hoje durou; está a ponto de submergi-lo no passado, e se entregar à tarefa de sua transformação. Certamente, o espírito nunca está em repouso, mas sempre tomado por um movimento para frente. (...) Esse desmoronar-se gradual, que não alterava a fisionomia do todo, é interrompido pelo sol nascente, que revela num clarão a imagem do mundo novo ${ }^{42}$.
\end{abstract}

Na perspectiva hegeliana, coube ao cristianismo na história da humanidade o papel de proclamar que o homem é livre enquanto homem e que a liberdade é, portanto, específica do ser humano. O acontecimento de Cristo é, em Hegel, de significação universal, porque nele o ser humano toma consciência de que seu ser se identifica com a liberdade, pois a liberdade subjetiva enquanto consciência de sua transcendência sobre as condições externas em que o ser humano está inserido fundamenta-se na unidade entre Deus e o ser humano, que se revelou em Cristo. Este representa a superação da separação entre Deus e o homem, sendo a 
reconciliação entre ambos. A liberdade do homem revela-se possibilitada pela participação na liberdade absoluta.

Entretanto, o princípio da liberdade cristã permaneceu interior, não chegando a se tornar uma liberdade mundana. Como diz Hegel, no parágrafo 62 da Filosofia do Direito: "Há cerca de mil e quinhentos anos que a liberdade da pessoa começou a florescer graças ao cristianismo e tornou-se princípio universal entre uma parte, aliás, pequena, do gênero humano" ${ }^{\prime 3}$. Entretanto, só os tempos modernos começaram a tornar efetiva a significação do cristianismo na história da humanidade, à medida que a liberdade se fez o grande programa da modernidade em consequência da Reforma Protestante.

Por isso, Hegel vê uma passagem coerente entre o princípio cristão da liberdade pela Reforma Protestante e os movimentos emancipatórios da modernidade, como o lluminismo e a Revolução Francesa. Para Karl Löwith, a secularização do cristianismo original não significa, em Hegel, uma condenável traição de seu sentido original, mas, ao contrário, a verdadeira explicação dessa origem "mediante sua realização positiva"44. Não à toa Taylor destaca que, em Hegel, "o entrelaçamento entre religião e lluminismo jamais poderia constituir dois campos opostos, como na França"45.

Para que o princípio cristão da liberdade pudesse perpassar a realidade sociopolítica, foi necessário que o Estado se libertasse das igrejas cristãs particulares. Tal cisão permitiu a realização da verdade do cristianismo. Hegel aceita, por um lado, a necessária emancipação do homem por meio da Revolução Francesa.

Todavia, diz Hegel, o lluminismo criticou também as representações cristãs, reduzindo seu conteúdo a objetos finitos. O lluminismo não percebeu, segundo Hegel, que a negação do absoluto implica a negação da subjetividade.

\footnotetext{
43 HEGEL, G. W. F. Filosofia do Direito. 3. ed. São Paulo: Loyola, 2010. p. 98.

44 LÖWITH, K. De Hegel a Nietzsche: a ruptura revolucionária no pensamento do século XIX: Marx e Kierkegaard. São Paulo: Unesp, 2014. p. 41.

45 TAYLOR, C. Hegel: sistema, método e estrutura. São Paulo: Realizações Editora, 2014. p. 33.
} 
O elemento positivo do lluminismo foi ter feito morrer certa concepção de Deus, manifestando a verdade do cristianismo, para além do cristianismo. Porém, o lluminismo não percebeu que a pura negação do absoluto significa a negação da subjetividade, pois implica seu aprisionamento ao finito.

Hegel, no parágrafo 270 da Filosofia do Direito, fala não apenas do caráter negativo do fanatismo religioso, mas também do fanatismo político, no contexto da Revolução Francesa: “(...) surge então o fanatismo religioso, que, como o fanatismo político, bane todas as instituições do Estado"46. Em Hegel, a liberdade é explicitada como síntese entre individualidade e sociabilidade, entendida como institucionalidade. A forma de configuração dessas instituições é que decide se elas são ou não expressão da autoconsciência dos indivíduos como seres livre.

Dessa forma, Hegel conserva o elemento positivo do lluminismo, recuperando o conteúdo central do cristianismo, a Encarnação do Verbo, que significa a superação do dualismo abstrato entre Deus e o homem livre. Do contrário, Hegel alerta que a sociedade estará sempre sujeita à tirania semelhante ao Terror Jacobino na Revolução Francesa, haja vista uma concepção estreita de liberdade, relacionada apenas com a interioridade. "Portanto, quando a razão fala de um Outro que ela, de fato, só fala de si mesma; assim não sai de si"47.

Na perspectiva hegeliana, como enfatiza Taylor, não reconhecendo a si mesmo no seu adversário, o lluminismo "entende mal a fé"48. O erro básico do lluminismo foi rejeitar a transcendência e tentar alcançar essa meta unicamente a partir do ser humano; "ele tenta tornar a subjetividade humana dominante de modo exclusivo, em vez de torná-la participante da dominação do sujeito absoluto"49.

\footnotetext{
46 HEGEL, G. W. F. Filosofia do Direito. 3. ed. São Paulo: Loyola, 2010. p. 244.

47 HEGEL, G. W. F. Fenomenologia do Espírito. 4. ed. São Paulo: Vozes, 2007. p. 377.

48 TAYLOR, C. Hegel: sistema, método e estrutura. São Paulo: Realizações Editora, 2014. p. 212.

49 TAYLOR, C. Hegel: sistema, método e estrutura. São Paulo: Realizações Editora, 2014. p. 210.
} 
Hegel, como destaca Habermas, "não é o primeiro filósofo que pertence aos tempos modernos, mas o primeiro para o qual a modernidade se tornou um problema"50. Hegel foi um dos pensadores da modernidade que reagiu contra os ataques do lluminismo ao cristianismo, ressaltando o grande valor da doutrina cristã. Em Hegel, a religião é uma grande fonte de motivação que orienta o ser humano inteiro para o Bem, pois o homem não é apenas racional, mas também uma criatura sensível. "Por isso, desde o começo, Hegel não assumiu a posição do austero lluminismo sobre a religião, de que em nada se pode acreditar senão naquilo que a razão autoriza"51. Segundo Hegel, carece de fundamento uma secularização que pretenda superar pura e simplesmente o cristianismo, suas fontes de sentido e mesmo uma comunidade formadora das identidades dos sujeitos, algo que influenciou diretamente o pensamento de Taylor.

\section{Por uma redefinição do secularismo}

Para Taylor, seguindo sua interpretação hegeliana, seria ilusória a tentativa secular de estabelecer a prioridade de seu discurso frente ao religioso. "Concorda-se geralmente que as democracias modernas devem ser 'seculares': (...) certo etnocentrismo está entrelaçado a esse termo ${ }^{52 "}$. Sobre o secularismo, Taylor explica que a maneira secular de ver o mundo, separando algo terreno e deste mundo de algo transcendente, é parte apenas do nosso modo de ver as coisas como ocidentais: "Tendemos a aplicá-la universalmente, embora nenhuma distinção tão rígida tenha existido em qualquer outra cultura humana na história"53.

\footnotetext{
50 .HABERMAS, J. O discurso filosófico da modernidade. São Paulo: Martins Fontes, 2002. p. 62.

51 TAYLOR, C. Hegel: Sistema, Método e Estrutura. São Paulo: Realizações Editora, 2014, p.77.

52 TAYLOR, C. O que significa secularismo? In: ARAÚJO, L.; MARTINEZ, M.; PEREIRA, T. (org.). Esfera pública e secularismo: ensaios de filosofia política. Rio de Janeiro: UERJ, 2012, p.166.

53 TAYLOR, C. O que significa secularismo? In: ARAÚJO, L.; MARTINEZ, M.; PEREIRA, T. (org.). Esfera pública e secularismo: ensaios de filosofia política. Rio de Janeiro: UERJ, 2012, p.16o.
} 
Como contextualiza Taylor, o secular tem a ver com o "século", isto é, com o tempo profano, contrastando com o eterno e o sagrado. Há um significado de secularização que data da sequência da Reforma, a partir do momento que certas funções, propriedades e instituições foram transferidas do controle eclesiástico para o dos leigos. Do século XVII em diante consoante Taylor, uma nova possibilidade aparece gradualmente, a saber: uma concepção de vida social na qual o secular era tudo o que havia, sem qualquer referência ao sagrado. Na era secular, diz Taylor, torna-se inaceitável qualquer forma de religião pública:

(...) a chegada da secularidade moderna, a meu ver, foi coincidente com o surgimento de uma sociedade na qual, pela primeira vez na história, um humanismo puramente autossuficiente tornou-se uma opção amplamente disponível. Quero dizer com isso um humanismo que não aceita quaisquer objetivos finais além do próprio florescimento humano, nem qualquer lealdade a nada além desse florescimento. Isto não ocorreu com nenhuma outra sociedade ${ }^{54}$.

A fé passa a ser relegada à esfera privada, havendo, de acordo com a visão secular de mundo, uma moral independente de qualquer referência transcendente, bem como a defesa de uma razão sem auxílio a fontes transcendentes, derivadas da Revelação. Essa é a principal crítica de Taylor a determinada concepção do secular a qual ele se opõe, por supostamente não levar em conta as identidades formadoras dos sujeitos, isto é, as possíveis referências de sentido do agir humano, como as tradições religiosas. Um exemplo de secularidade que Taylor critica é aquela defendida por John Rawls em O liberalismo político, uma vez que Rawls defende a separação entre as identidades públicas e privadas nos crentes.

Rawls defende que os cidadãos devem votar com base na ordenação de valores políticos, e não metafísicos. Quando, diz ele, os cidadãos se convertem a outra religião ou não professam mais uma fé religiosa, não

54 TAYLOR, C. Uma era secular. São Leopoldo: Unisinos, 2010a. p. 31. 
deixam de ser, no que diz respeito a questões de justiça política, as mesmas pessoas de antes. Segundo Rawls, não há nenhuma perda de suas identidades públicas ou institucionais. Eles continuam conservando os mesmos direitos e deveres, podendo fazer as mesmas demandas de antes.

Sobre isso, Rawls cita o seguinte exemplo: no caminho para Damasco, Saulo de Tarso transforma-se em Paulo, o Apóstolo. No entanto, tal conversão não implica nenhuma mudança na identidade pública ou institucional. De acordo com Rawls, para os propósitos de uma vida pública, Saulo de Tarso e o Apóstolo São Paulo são a mesma pessoa: "A conversão é irrelevante para nossa identidade pública ou institucional" 55 .

Ele destaca que os próprios cidadãos, voltando-se para suas doutrinas abrangentes, podem relacionar a concepção política como derivada de outros valores seus, ou congruentes com eles, ou pelo menos não contraditórios com tais valores. Contudo, ele esclarece que uma concepção política de justiça é formulada como uma visão que se sustenta por si própria, o que não significa que uma concepção política não possa coincidir com doutrinas abrangentes ou mesmo não as contradizer.

Rawls destaca que, na razão pública, é possível permitir que se introduza na discussão política nossa doutrina abrangente, religiosa ou não, contanto que ofereçamos razões adequadamente públicas para apoiar os princípios e as políticas que se acredita que nossa doutrina abrangente sustente. Embora a visão ampla da cultura política pública permita introduzir, por exemplo, uma parábola do Evangelho, a razão pública exige que justifiquemos nossa proposta com base em valores políticos adequados.

Rawls fala que diante de impasses na ordem do político os cidadãos não podem recorrer às razões mais fundamentais de suas doutrinas abrangentes. Ele destaca que os cidadãos deveriam votar com base numa ordenação de valores políticos, e não metafísicos. Rawls enfatiza ser desejável que as diversas doutrinas abrangentes, como as religiosas, sejam deixadas de lado

55 RAWLS, J. O liberalismo político. São Paulo: Martins Fontes, 2011. p. 38. 
na razão pública, o que Taylor critica fortemente, porque isso violaria as identidades dos sujeitos, bem como suas fontes de sentido de vida.

Em sua crítica a Rawls, Taylor defende que não se pode exigir que todos deliberem numa linguagem secular, deixando suas visões religiosas de fora, tal qual Rawls afirma, como vimos antes, ao propor a separação entre identidades religiosas das não religiosas na razão pública. Sobre isso, Taylor argumenta:

A questão de Rawls ao sugerir essa restrição era a de que todos deveriam usar uma linguagem com a qual poderiam razoavelmente esperar que seus concidadãos concordassem. A ideia parece ser algo assim: a razão secular é uma linguagem que todos falam e podem argumentar a ser convencidos. As linguagens religiosas operam fora desse discurso, introduzindo premissas irrelevantes que só os crentes podem aceitar. Então, vamos falar a linguagem comum ${ }^{56}$.

A tese rawlsiana ressalta sempre o seguinte aspecto: os cidadãos possuem uma identidade pública e outra privada. Na razão pública, as justificações devem ser guiadas por argumentos da ordem da identidade pública. Entrementes, não seria possível, em Taylor, uma separação rigorosa no mesmo sujeito entre uma identidade privada (de um crente) de uma pública (não religiosa) como defende Rawls.

Segundo Taylor, nem todas as sociedades passaram por processos de secularização em que as identidades dos sujeitos não foram formadas a partir de uma visão de mundo secular: "Eu não concordo, particularmente, com a distinção entre ética e religião" ${ }^{57}$. Para Taylor, a democracia requer que todo cidadão utilize, no debate público, a linguagem que seja mais

\footnotetext{
56 TAYLOR, C. O que significa secularismo? In: ARAÚJO, L.; MARTINEZ, M.; PEREIRA, T. (org.). Esfera pública e secularismo: ensaios de filosofia política. Rio de Janeiro: UERJ, 2012. p. 184.

57 TAYLOR, C. Why we need a radical redefinition of secularism: “I don't agree, particular, about the distinction between ethics and religion". Ver em: In: MENDIETA, E.; VANANTWERPEN, J. (ed.). The power of religion in the public sphere. New York: Columbia University, 2011a. p. 62.
} 
significativa para todos. Em alguns casos, argumenta Taylor, é inevitável a formulação nos parâmetros da religião:

Os compatriotas seculares de Martin Luther King foram incapazes de compreender o que ele estava defendendo quando expressou a questão da igualdade em termos bíblicos? Mais pessoas teriam entendido a questão se ele tivesse invocado Kant? ${ }^{58}$

Taylor destaca que um kantiano, por exemplo, justificará os direitos à vida e à liberdade apontando para a dignidade humana; já um utilitarista defenderá a necessidade de tratar os seres que podem experimentar prazer ou dor, de tal forma que maximize o primeiro e minimize a segunda; finalmente, um cristão falará dos seres humanos como feitos à imagem de Deus. "Eles concordam nos princípios, mas diferem nas razões mais profundas para aderir a essa ética" ${ }^{59}$. Assim, a secularização teria que se abrir às argumentações e linguagens religiosas que formam as identidades dos mais diversos sujeitos, tal qual uma fonte de sentido de vida.

Por conseguinte, somente no interior de um horizonte de valores de uma tradição seria possível colocar as questões da justiça e, assim, responder sobre o que é bom e o que deve valer para a comunidade, considerando o pano de fundo de suas avaliações e de sua autocompreensão.

Não estou defendendo nenhuma tese "pós-moderna" no sentido de que cada um de nós está aprisionado em seu próprio ponto de vista e nada pode fazer para convencer racionalmente o outro. Pelo contrário, penso que podemos apresentar argumentos para induzir outros a modificar seus juízos e (o que está estritamente ligado a isso) a ampliar suas simpatias. Porém, essa tarefa é muito difícil e, o que é mais importante, jamais estará completa. Nós não nos decidimos de uma vez por todas deixar nossos valores. Eles não contam

\footnotetext{
58 TAYLOR, C. O que significa secularismo? In: ARAÚJO, L.; MARTINEZ, M.; PEREIRA, T. (org.). Esfera pública e secularismo: ensaios de filosofia política. Rio de Janeiro: UERJ, 2012. p. 187.

59 TAYLOR, C. O que significa secularismo? In: ARAÚJO, L.; MARTINEZ, M.; PEREIRA, T. (org.). Esfera pública e secularismo: ensaios de filosofia política. Rio de Janeiro: UERJ, 2012. p. 160.
} 
apenas como premissas conscientes que podemos descontar. Eles continuam a moldar nosso pensamento em um nível mais profundo, e somente um intercâmbio franco continuado com quem tem pontos de vista diferentes nos ajudará a corrigir algumas distorções que eles engendram ${ }^{60}$.

Para Taylor, o projeto do secularismo de justificar uma moralidade independente das tradições culturais e religiosas fracassou. Seria preciso, segundo ele, repensar um novo sentido do secularismo que considere as tradições, religiões e as diversas linguagens como fontes essenciais na formação e constituição das identidades dos sujeitos, como fontes de sentido para o próprio viver.

Afinal, como sempre ressalta Taylor ${ }^{61}$, vivemos em um mundo em que ideias, instituições, estilos artísticos e fórmulas para a produção e a vida circulam entre sociedades e civilizações que são bem diferentes em suas raízes históricas e formas tradicionais. A crença em uma religião significa, em outros termos, uma articulação crucial para determinada forma de mundo moral, no sentido de uma descrição de um modo de vida ${ }^{62 "}$.

\section{Referências}

ARAÚJO, P. Charles Taylor: para uma ética do reconhecimento. São Paulo: Loyola, 2004.

BERGER, P. Os múltiplos altares da modernidade: rumo a um paradigma da religião numa época pluralista. Petrópolis: Vozes, $2017 a$.

BERGER, P. O Imperativo Herético: possibilidades contemporâneas da afirmação religiosa. Petrópolis: Vozes, 2017b.

\footnotetext{
60 TAYLOR, C. Uma era secular. São Leopoldo: Unisinos, 2010a. p. 502.

${ }_{61}$ TAYLOR, C. O que significa secularismo? In: ARAÚJO, L.; MARTINEZ, M.; PEREIRA, T. (org.). Esfera pública e secularismo: ensaios de filosofia política. Rio de Janeiro: UERJ, 2012. p. 170.

${ }^{62}$ TAYLOR, C. As fontes do self: a constituição da identidade moderna. 4. ed. São Paulo: Edições Loyola, 2013. p. 106.
} 
BINJA, E. Multiculturalismo: a identidade do sujeito nas tensões sociais contemporâneas em Charles Taylor. São Paulo: Editora LiberArs, 2015.

HABERMAS, J. O discurso filosófico da modernidade. São Paulo: Martins Fontes, 2002.

HEGEL, G. W. F. Fenomenologia do Espírito. 4. ed. São Paulo: Vozes, 2007.

HEGEL, G. W. F. Filosofia do Direito. 3. ed. São Paulo: Loyola, 2010.

LÖWITH, K. De Hegel a Nietzsche: a ruptura revolucionária no pensamento do século XIX. Marx e Kierkegaard. São Paulo: Unesp, 2014.

OLIVEIRA, M. Ética e Sociabilidade. 3. ed. São Paulo: Loyola, 2003.

RAWLS, J. O liberalismo político. São Paulo: Martins Fontes, 2011.

RICOEUR, P. O Si Mesmo como um Outro. Campinas: Papirus Editora, 1991.

TAYLOR, C. Multiculturalismo: examinando a política de reconhecimento. Lisboa: Instituto Piaget, 1994.

TAYLOR, C. Argumentos Filosóficos. São Paulo: Edições Loyola, 2000.

TAYLOR, C. Hegel e a Sociedade Moderna. São Paulo: Edições Loyola, 2005.

TAYLOR, C. Uma era secular. São Leopoldo: Unisinos, $2010 a$.

TAYLOR, C. Imaginários sociais modernos. Lisboa: Edições Texto \& Grafia, $2010 b$.

TAYLOR, C. Why We need a radical redefinition of secularism. In: MENDIETA, E.; VANANTWERPEN, J. (ed.). The power of religion in the public sphere. New York: Columbia University, 2011a. p. 34-59.

TAYLOR, C. A ética da autenticidade. São Paulo: Realizações Editora, 2011b.

TAYLOR, C. O que significa secularismo? In: ARAÚJO, L.; MARTINEZ, M.; PEREIRA, T. (org.). Esfera pública e secularismo: ensaios de filosofia política. Rio de Janeiro: UERJ, 2012. p. 157-195.

TAYLOR, C. As fontes do self: a constituição da identidade moderna. 4. ed. São Paulo: Edições Loyola, 2013.

TAYLOR, C. Hegel: sistema, método e estrutura. São Paulo: Realizações Editora, 2014.

WALZER, M. Da Tolerância. São Paulo: Martins Fontes, 1999. 